Methods: We extracted data on all patients identified in the WA Hospital Morbidity Data Collection between 1995 and 2014, with the International Classification of Diseases (ICD) codes for RA (ICD 10 M05.00-M06.99, and the corresponding ICD 9 codes). We estimated period prevalence rates per 1000 hospital separations and annual average percentage changes, with the total number of hospital separations each year.

Results: A total of 17,125 patients were admitted to WA hospitals with a diagnostic code for RA over the study period (1995-2014). The total number of hospital separations for RA patients was 50,353 , indicating an average of three hospital separations per patient over twenty years. The RA prevalence was 3.4 per 1000 separations over the study period, with a $-2.89 \%$ annual average decrease since 1995.

Conclusion: These data demonstrate that hospitalisation for RA has decreased considerably in WA over the last two decades. As this decrease roughly coincides with the introduction of biological drug treatment for RA, the reduced need for hospital admission is likely due to improvements in RA management. REFERENCES:

[1] Uhlig T, Moe RH, Kvien TK (2014) The burden of disease in rheumatoid arthritis. Pharmacoeconomics 32:841-851. doi:10.1007/s40273-014-0174-6

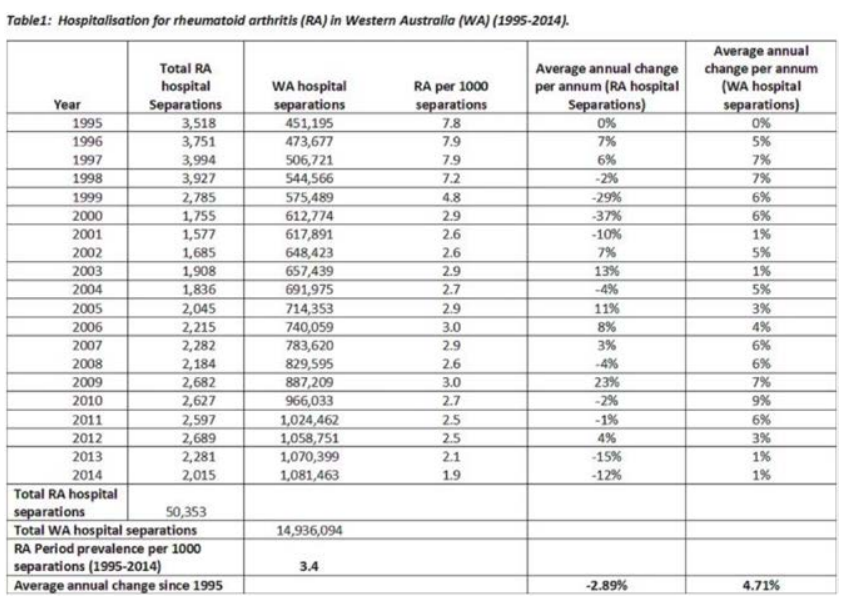

Acknowledgements: Khalid Almutairi was supported by an Australian Government Research Training Program PhD Scholarship at the University of Western Australia.

Disclosure of Interests: Khalid Almutairi: None declared, Johannes Nossent Speakers bureau: Janssen, David Preen: None declared, Helen Keen Speakers bureau: Pfizer Australia, Abbvie Australia, Charles Inderjeeth Speakers bureau: Eli Lilly

DOI: 10.1136/annrheumdis-2021-eular.339

\section{POS0298 UNDERSERVED POPULATIONS IDENTIFY BARRIERS AND PROPOSE SOLUTIONS FOR SELF-MANAGING ARTHRITIS AND CHRONIC CONDITIONS}

S. Mills ${ }^{1}$, K. Khehra ${ }^{2}$, P. Ghuman ${ }^{2}$, D. Au $^{3}$, C. L. Koehn ${ }^{4}$, R. Maynard ${ }^{5}$, N. Clark ${ }^{6,7}$, C. Davis ${ }^{8}$, A. Cui ${ }^{9}$, C. B. Hamilton ${ }^{2,10}$, D. Lacaille ${ }^{2,10} .{ }^{1}$ University of British Columbia, Deparment of Medicine, School of Population and Public Health, Vancouver, Canada; ${ }^{2}$ University of British Columbia, Department of Medicine, Faculty of Medicine, Vancouver, Canada; ${ }^{3}$ MOSAIC (Multi-lingual Orientation Service Association for Immigrant Communities), Vancouver, Canada; ${ }^{4}$ Arthritis Consumer Experts, Vancouver, Canada; ${ }^{5}$ Portland Hotel Society Community Services Society, Vancouver, Canada; ${ }^{6}$ University of Victoria, School of Nursing, Victoria, Canada; ${ }^{7}$ University of British Columbia, Centre for Migration Studies, Vancouver, Canada; ${ }^{8}$ Centre for Collaboration, Motivation and Innovation, Vernon, Canada; ${ }^{9}$ University of British Columbia, Vancouver, Canada; ${ }^{10}$ Arthritis Research Canada, Vancouver, Canada

Background: Underserved populations, such as ethnic minorities, low-income adults, and Indigenous people living with arthritis are more likely to have lower health literacy, higher rates of multi-morbidity, and face challenges in accessing care $^{1-3}$. Self-management support (SMS) can help to mitigate the impacts of living with arthritis ${ }^{4}$. However, we require a more in-depth understanding of the daily barriers underserved communities face in living with arthritis in order to develop effective SMS that can meaningfully improve well-being and quality of life.

Objectives: The study objective was to bring together underserved people living with arthritis to identify common barriers they face in taking care of their conditions in daily life, and to identify their solutions to the identified challenges.

Methods: A team of researchers from several universities, nurse practitioners, physicians, policy makers, an arthritis consumer-patient leader and our community partners (Multi-lingual Orientation Service Association for Immigrant Communities and the Portland Hotel Society Community Services Society) engaged in a Community-based Participatory and Concept Mapping (CM) study $^{5-7}$ where participants from underserved communities identified major barriers they face in managing arthritis, agreed on key themes that emerged, and determined priorities for actions. This involved three key $\mathrm{CM}$ activities: 1) brainstorming ideas; 2) sorting and rating ideas; and 3) analyzing and interpreting concept maps ${ }^{8}$. Data was collected through face-to-face interviews and prioritized and interpreted in workshop settings.

Results: Sixty-three individuals who were ethnic minorities, immigrants, refugees, low-income, over 65, and/or housing insecure and living with arthritis identified 35 common barriers and made recommendations in the areas of financial difficulties, social services, access to health services, quality of health services, lack of knowledge, and mental health. Additional funding has been sought through Community-University Engagement Support Funding to enable our community partners to prioritize the recommendations in their communities, and to develop mechanisms for implementation using already existing community structures, processes, and services.

Conclusion: Persons living with arthritis in diverse underserved communities face significant health and social inequities, including lack of access to basic life necessities such as food, housing, employment, and safety, which creates barriers to self-managing arthritis and other chronic conditions in daily life. SMS for these communities needs to address these social and environmental bar riers shaping capacity for self-management, and ultimately, quality of life and well-being.

REFERENCES:

[1] Ackerman I, Busija L. Access to self-management education, conservative treatment and surgery for arthritis according to socioeconomic status. Best Pr Res Clin Rheumatol. 2012;26(5):561-83.

[2] Shadmi E. Multimorbidity and equity in health. Int $J$ Equity Heal 2013;12(59):59.

[3] Foster M, Kendall E, Dickson P, Chaboyer W, Hunter B, Gee T. Participation and chronic disease self-management: are we risking inequitable resource allocation? Aust J Prim Health. 2003;9(3):132-40.

[4] Brady T, Anderson L, Kobau R. Chronic disease self-management support: public health perspectives. Front Public Heal. 2015;2(234).

[5] Trochim W. An introduction to concept mapping for planning and evaluation. Eval Progr Plann. 1989;12(1):1-16.

[6] Anderson L, Day K, Vandenberg A. Using a concept map as a tool for strategic planning: the healthy brain initiative. Prev Chronic Dis. 2011;8(5):A117.

[7] Petrucci C, Quinlan K. Bridging the research practice gap: concept mapping as a mixed methods strategy in practice-based research and evaluation. $J$ Soc Serv Res. 2007;34(2):25-42.

[8] Kane M, Trochim W. Concept mapping for planning and evaluation. Thousand Oaks (CA): SAGE Publications; 2007.

Disclosure of Interests: None declared

DOI: 10.1136/annrheumdis-2021-eular.2211

\section{\begin{tabular}{|l|l}
\hline POS0299 SOCIOECONOMIC BACKGROUND IS ASSOCIATED \\
\hline
\end{tabular} WITH DISCORDANCE BETWEEN HEALTH LITERACY OF PEOPLE WITH RMDS AND ASSESSMENT OF HEALTH LITERACY BY THEIR TREATING HEALTH PROFESSIONAL}

M. M. Bakker ${ }^{1,2}$, C. Dikovec ${ }^{1}$, P. Putrik ${ }^{1,2}$, J. Rademakers $^{2,3}$, M. Van de Laar $^{4}$, H. Vonkeman ${ }^{4,5}$, M. R. Kok ${ }^{6}$, H. Voorneveld ${ }^{6}$, S. Ramiro ${ }^{7,8}$, M. De Wit ${ }^{9}$, R. Buchbinder ${ }^{10,11}$, R. Batterham ${ }^{12,13}$, R. Osborne ${ }^{12}$, A. Boonen ${ }^{1,2} .{ }^{1}$ Maastricht University Medical Centre, Internal Medicine, Rheumatology Division, Maastricht, Netherlands; ${ }^{2}$ Maastricht University, CAPHRI - Care and Public Health Research Institute, Maastricht, Netherlands; ${ }^{3}$ Nivel - Netherlands Institute for Health Services Research, -, Utrecht, Netherlands; ${ }^{4}$ University of Twente, Psychology, Health and Technology, Enschede, Netherlands; ${ }^{5}$ Medisch Spectrum Twente, Arthritis Center Twente - Rheumatology and Clinical Immunology, Enschede, Netherlands; ${ }^{6}$ Maasstad Hospital, Rheumatology and Clinical Immunology, Rotterdam, Netherlands; ${ }^{7}$ Leiden University Medical Centre, Rheumatology, Leiden, Netherlands; ${ }^{8}$ Zuyderland Medical Centre, Rheumatology, Heerlen, Netherlands; ${ }^{9}$ Tools2Use Patient Association, -, Amsterdam, Netherlands; ${ }^{10}$ Monash University, School of Public Health and Preventive Medicine, Melbourne, Australia; ${ }^{11}$ Cabrini Institute, Monash Clinical Epidemiology, Melbourne, Australia; ${ }^{12}$ Swinburne University of Technology, Centre for Global Health and Equity, Melbourne, Australia; ${ }^{13}$ Thammasat University, Faculty of Public Health, Bankok, Thailand

Background: Health literacy is increasingly recognised as a critical determinant of health. While care should be tailored to the health literacy needs of each patient [1], research in primary care shows that physicians often under- or overestimate their patients' health literacy, with socioeconomic factors playing a role [2]. Evidence in a rheumatology setting is scarce. 